\title{
KOMBINASI METODE ISOMAP DAN KNN PADA IMAGE PROCESSING UNTUK PENGENALAN WAJAH
}

\author{
Rifki Kosasih ${ }^{1}$ \\ ${ }^{1}$ Program Studi Komputasi Matematika, Fakultas Teknik Informatika, Universitas Gunadarma \\ Jl. Margonda Raya No. 100, Depok, Indonesia 16424 \\ ${ }^{1}$ rifki_kosasih@staff.gunadarma.ac.id
}

Abstrak - Wajah manusia memiliki ciri khusus yang dapat membedakan dengan orang lainnya sehingga pengenalan wajah sangat penting dilakukan untuk mengenali seseorang. Ciri khusus pada wajah ini disebut juga dengan fitur. Pada penelitian ini, untuk mendapatkan fitur dilakukan pengenalan pola citra wajah dengan menggunakan metode isomap. Metode isomap merupakan salah satu metode dari manifold learning yang menghasilkan fitur-fitur dengan cara mereduksi dimensi. Citra wajah yang digunakan dalam penelitian ini terdiri dari 6 orang dengan tiap orang memiliki 4 citra wajah dengan ekspresi yang berbeda-beda. Data citra ini dibagi menjadi dua bagian yaitu data latih dan data uji. Selanjutnya data citra tersebut diubah menjadi vektor. Metode isomap digunakan untuk mentransformasikan vektor tersebut menjadi vektor yang mengandung fitur wajah. Setelah fitur wajah diperoleh, selanjutnya dilakukan pengujian pada data uji dengan menggunakan algoritma $K$ Nearest Neighbor (KNN). Algoritma $\mathrm{K}$ Nearest Neighbor digunakan untuk pengklasifikasian dengan cara mencari $\mathbf{K}$ data latih yang terdekat dengan data uji. Dari hasil klasifikasi diperoleh bahwa tingkat akurasi sebesar $83,33 \%$.

Kata Kunci- fitur, isomap, manifold learning, KNN.

Abstract- Human face has a special feature that can differentiate with other people so that facial recognition is very important to recognize someone. Special features on this face are also called features. In this study, to obtain features, pattern recognition of facial image is done using the Isomap method. The isomap method is one of the methods of the manifold learning that produces features by reducing dimensions. Face images used in this study consisted of 6 people with each person having 4 face images with different expressions. This image data is divided into two parts, namely training data and test data. Furthermore, the image data is converted into vectors. The isomap method is used to transform the vector into a vector that contains facial features. After facial features are obtained, then testing is done on the test data using the $K$ Nearest Neighbor (KNN) algorithm. The $K$ Nearest Neighbor algorithm is used for classification by finding the $K$ training data closest to the test data. From the classification results obtained that the level of accuracy is $83,33 \%$.

Keywords - features, isomap, manifold learning, KNN.

\section{PENDAHULUAN}

Untuk mengenali seseorang, biasanya dilakukan dengan cara melihat wajahnya karena tiap wajah seseorang memiliki ciri khusus (fitur) yang membedakan dengan orang yang lainnya. Dalam bidang keamanan, absensi dan lain-lain, Pengenalan wajah sangat dibutuhkan. Dalam bidang computer vision, wajah seseorang dapat dikenali dengan bantuan komputer.

Salah satu cara untuk mengenali wajah seseorang adalah dengan melakukan pengenalan pola citra wajah. Metode yang sering dipakai dalam pengenalan pola adalah metode manifold learning. Manifold learning merupakan suatu metode mereduksi dimensi dari dimensi besar menjadi dimensi yang lebih kecil tanpa menghilangkan banyak informasi [1]. Metode isomap merupakan salah satu metode manifold learning yang digunakan untuk mereduksi fitur yang berdimensi tinggi menjadi fitur yang berdimensi yang lebih rendah dan diaplikasikan untuk pengenalan pola [2], [3].

Metode isomap pertama kali diperkenalkan oleh Tenenbaum pada tahun 2000 [4]. Dalam penelitiannya, Tenenbaum menggunakan metode isomap untuk mengamati pola pergerakkan wajah dan pergerakkan tangan [4].

Pada penelitian terdahulu, kosasih, melakukan pengklasteran wajah manusia dengan menggunakan metode isomap. Dalam penelitiannya, kosasih menggunakan citra yang berasal dari 5 orang dengan tiap orang memiliki 4 citra dengan berbagai ekspresi. Dari hasil penelitiannya citra-citra wajah yang berasal dari orang yang sama dengan ekspresi wajah yang berbeda-beda mengelompok ke dalam satu area akan tetapi dalam penelitiannya belum dilakukan pengujian dengan menggunakan metode klasifikasi wajah [5]

Untuk itu dalam penelitian ini untuk mendapatkan fitur pengenalan wajah digunakan metode isomap dan 
dilakukan pengujian pengklasifikasian wajah untuk mengenali wajah seseorang dengan menggunakan algoritma $K$ Nearest Neighbor (KNN). Algoritma K Nearest Neighbor digunakan untuk klasifikasi wajah dengan cara mencari $\mathrm{K}$ data latih yang terdekat dengan data uji.

Beberapa penelitian telah dilakukan dibidang pengenalan wajah seperti fahrurozi menggunakan metode Principle Component Analysis (PCA) dan Local Binary Pattern (LBP) untuk melakukan pengenalan wajah. Dalam penelitiannya LBP dan PCA digunakan untuk mendapatkan fitur wajah. Tingkat akurasi yang diperoleh untuk mengenali wajah seseorang adalah sebesar 75\% [6].

Selanjutnya Pratiwi menggunakan metode Principle Component Analysis (PCA) untuk melakukan pengenalan wajah. Dalam penelitianya tentang pengenalan wajah diperoleh bahwa tingkat akurasi dengan metode tersebut sebesar $82,81 \%$ [7].

\section{METODOLOGI}

Dalam penelitian ini, tahapan-tahapan penelitian dapat dilihat pada Gbr. 1. Tahapan awal dalam penelitian ini adalah melakukan pengumpulan data citra wajah.

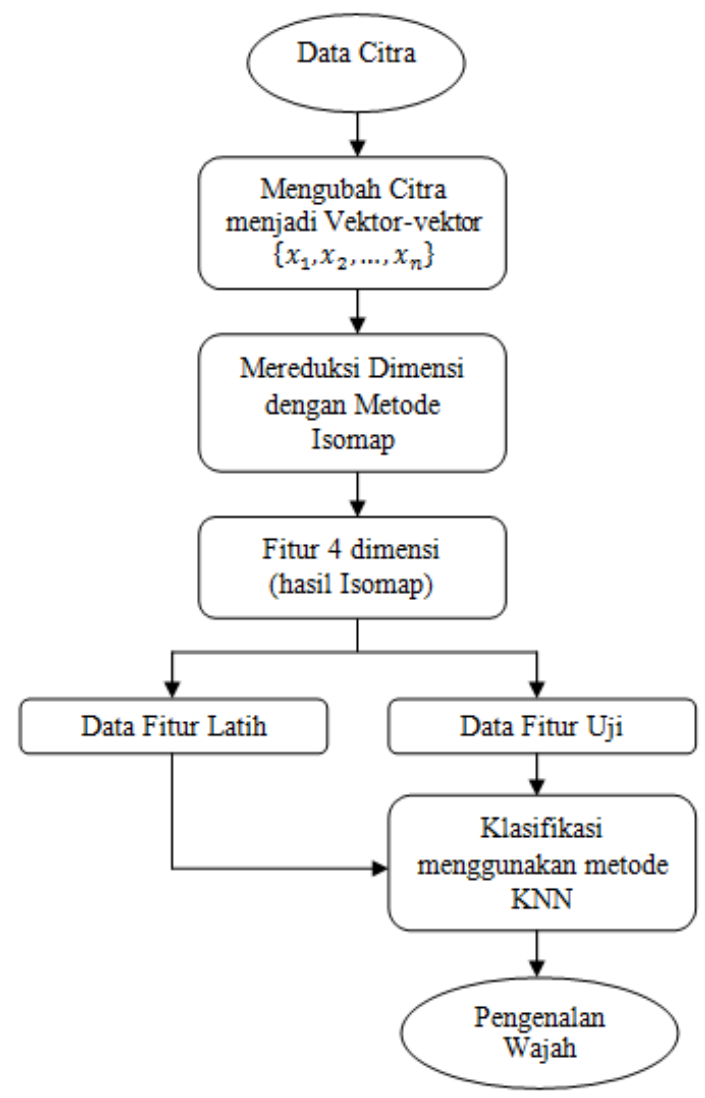

Gbr 1. Tahapan Penelitian

Data citra wajah yang dikumpulkan terdiri dari 6 orang dengan tiap orang memiliki 4 citra dengan ekspresi yang berbeda-beda sehingga total data yang digunakan adalah 24 citra yang berukuran $280 \times 315$.
Sampel citra tersebut diperoleh dari ORL database dan dapat dilihat pada Gbr. 2.

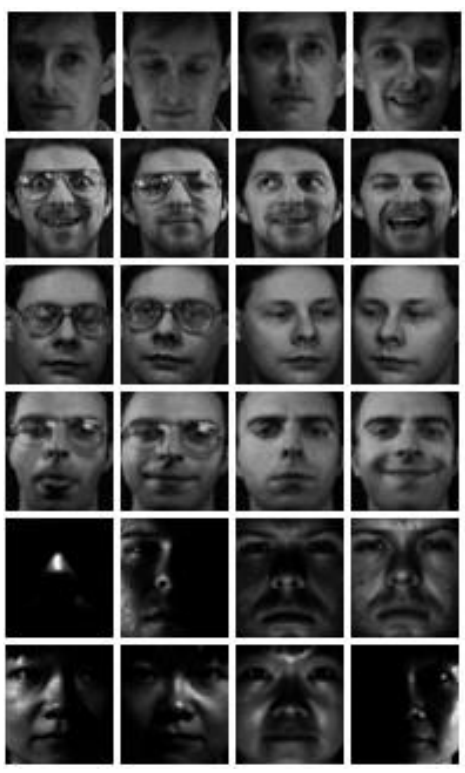

Gbr. 2. Sampel Citra Wajah

Untuk menganalisis citra-citra tersebut, setiap matriks representasi citra, misalkan berukuran $\mathrm{MxN}$, diubah menjadi vektor kolom dengan cara mengurutkan kolom kedua dibawah kolom pertama, kolom ketiga dibawah kolom kedua, dan seterusnya, hingga diperoleh vektor kolom berukuran MNx1. Setiap vektor kolom yang telah dibuat diasumsikan sebagai sebuah simpul. Simpul-simpul tersebut kemudian diaplikasikan pada metode isomap [5]. Langkah-langkah dari metode isomap dapat dilihat pada Gbr. 3.

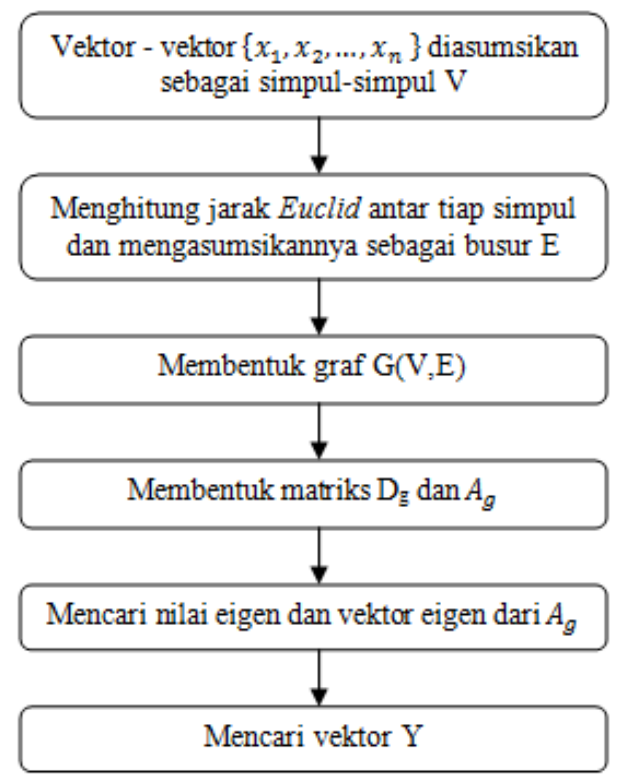

Gbr 3. Langkah-Langkah Metode Isomap

Pada Gbr. 3, citra-citra yang telah diperoleh diasumsikan sebagai simpul $\mathrm{x}_{\mathrm{i}}$ dengan $\mathrm{i}=1,2,3 \ldots, \mathrm{n}$. 
Selanjutnya konstruksi graf $\mathrm{G}(\mathrm{V}, \mathrm{E})$ dengan setiap simpul $\mathrm{V}$ adalah citra-citra wajah dan busur $\mathrm{E}$ adalah bobot antara 2 simpul. Bobot tersebut diperoleh dengan menghitung jarak Euclid dari 2 simpul.

Graf $\mathrm{G}(\mathrm{V}, \mathrm{E})$ diperoleh dengan cara menentukan nilai $\mathrm{k}$ pada metode K-nearest neighbors yang diimplementasikan pada himpunan simpul-simpul yang telah diperoleh [4]. Tahapan selanjutnya adalah menghitung jarak geodesi berdasarkan jalur terpendek antara simpul-simpul yang ada di graf $\mathrm{G}(\mathrm{V}, \mathrm{E})$. Metode jalur terpendek yang dipakai dalam penelitian ini adalah metode Floyd Warsyall [8].

Hasil perhitungan jarak geodesi merupakan matriks $\mathrm{D}_{\mathrm{g}}$ yang berukuran $n \times n$. Setelah itu, lakukan proses embedding ke dimensi yang lebih rendah dengan membentuk matriks $A_{g}$ yang dapat dilihat pada (1).

$$
A_{g}=-\frac{P D_{g}^{2} P}{2}
$$

dengan $P=I-\frac{1}{n} 11^{T}$

I merupakan matriks identitas, 1 merupakan vektor kolom yang semua anggotanya adalah 1 , dan $D_{g}^{2}$ merupakan matriks yang setiap anggotanya adalah kuadrat dari setiap anggota $D_{g}$.

Tahapan awal dalam penelitian ini adalah melakukan pengumpulan data citra wajah yang terdiri dari 6 orang dengan tiap orang memiliki 4 citra dengan ekspresi yang berbeda-beda sehingga total data yang digunakan adalah 24 citra yang berukuran sama. Sampel citra tersebut diperoleh dari ORL database dan dapat dilihat pada Gambar 2.

Tahapan berikutnya adalah mencari nilai eigen $\lambda_{i}$ dan vektor eigen $v_{i}$ dengan i $=1,2, \ldots, \mathrm{n}$ dari matriks $A_{g}$ untuk mendapatkan matriks Y seperti pada (2).

$$
Y=\left[\sqrt{\lambda_{1}} v_{1}, \sqrt{\lambda_{2}} v_{2}, \ldots, \sqrt{\lambda_{n}} v_{n}\right]^{T}
$$

Matriks Y merupakan solusi dari metode isomap yang berdimensi lebih rendah. Y berisi fitur-fitur hasil transformasi metode isomap. Fitur-fitur ini selanjutnya digunakan untuk pengenalan wajah. Dalam penelitian ini, fitur-fitur hasil metode isomap dibagi menjadi dua yaitu fitur latih dan fitur uji.

Tahapan selanjutnya adalah melakukan klasifikasi data uji yang belum diketahui kelasnya dengan menggunakan algoritma KNN.

\section{A. K Nearest Neighbor (KNN)}

Algoritma K Nearest Neighbor (KNN) merupakan algoritma pengklasifikasian objek berdasarkan keserupaan dengan objek lain yang didekatnya tanpa harus mengetahui distribusi dari data [9]. Oleh karena itu, jika terdapat data yang belum diketahui kelasnya maka dapat diprediksi dengan melihat sampel tetangga terdekat di sekitarnya [10], [11].

Berikut ini adalah algoritma KNN.

Algoritma KNN

input: Data Latih

Data Uji yang belum diketahui kelasnya
1. Tentukan nilai $\mathrm{K}$

2. Hitung jarak dari data uji yang belum diketahui ke semua data latih

3. Pilih $\mathrm{K}$ pengamatan dalam data latih yang terdekat dengan data uji yang belum diketahui

4. Prediksi kelas dari data uji yang belum diketahui dengan menggunakan nilai dari $\mathrm{K}$ data latih yang telah dipilih.

\section{HASIL DAN PEMBAHASAN}

Berdasarkan tahapan penelitian yang telah dilakukan data citra masukkan yang digunakan adalah citra wajah yang berasal dari 6 orang dengan tiap orang mempunyai 4 citra wajah dengan berbagai ekspresi. Citra-citra tersebut berukuran $280 \times 315$. Data citra tersebut diubah menjadi vektor-vektor kolpm yang berdimensi 88200 .

Tahapan selanjutnya adalah menggunakan metode isomap untuk mendapatkan fitur-fitur pengenalan wajah. Dalam penelitian ini, vektor-vektor yang berdimensi tinggi tersebut direduksi menjadi vektor yang berdimensi 4 . Vektor-vektor tersebut selanjutnya digunakan sebagai fitur pengenalan wajah. Hasil dari metode isomap dapat dilihat pada Tabel I.

Pembagian fitur latih dan fitur uji menggunakan metode $n$-fold validation. Metode $\mathrm{n}$-fold validation merupakan metode yang digunakan untuk membagi data latih dan data uji dengan bergantung nilai $n$ yang dipakai [12]. Nilai $n$ tersebut menentukan banyaknya iterasi yang digunakan.

Dalam penelitian ini, digunakan nilai $n=3$ sehingga 24 data citra yang sudah dikumpulkan dibagi menjadi dua dengan komposisi $\frac{2}{3}$ dari $24=16$ fitur lat(i) dan $\frac{1}{3}$ dari $24=8$ fitur uji. karena nilai $n=3$ maka jumlah iterasi yang digunakan sebanyak 3 .

Untuk iterasi ke-1, data uji yang digunakan adalah 8 data pertama dari 24 data. Untuk iterasi ke-2, data uji yang digunakan adalah 8 data yang berikutnya dari 45 data. Untuk iterasi ke-3, data uji yang digunakan adalah 8 data terakhir dari 24 data.

Fitur latih dan fitur uji untuk iterasi ke-1 dapat dilihat pada Tabel I dan Tabel II.

TABEL I

FITUR LATIH ITERASI KE-1

\begin{tabular}{|c|c|c|c|c|c|}
\hline & $\begin{array}{c}\text { Sb } \\
\text { Koord 1 }\end{array}$ & $\begin{array}{c}\text { Sb } \\
\text { Koord 2 }\end{array}$ & $\begin{array}{c}\text { Sb } \\
\text { Koord 3 }\end{array}$ & $\begin{array}{c}\text { Sb } \\
\text { Koord 4 }\end{array}$ & K \\
\hline 1 & 254,33 & $-2302,86$ & $-420,92$ & 2810,17 & 1 \\
\hline 2 & 3353,9 & 895,326 & $-1905,8$ & $-547,668$ & 1 \\
\hline 3 & $-1669,3$ & 5691,88 & 4499,2 & 3580,42 & 2 \\
\hline 4 & $-537,35$ & 8090,16 & 4172,71 & 906,221 & 2 \\
\hline 5 & $-1386,6$ & 7475,37 & 4079,72 & 387,302 & 2 \\
\hline 6 & $-3337,5$ & 4378,41 & $-3404,9$ & $-1299,32$ & 3 \\
\hline 7 & $-3752,1$ & 1644,93 & $-2640,3$ & $-4241,87$ & 3 \\
\hline 8 & $-1509,9$ & 3310,64 & $-2107,8$ & $-3009,61$ & 3 \\
\hline 9 & $-9293,9$ & $-3889,42$ & 392,470 & 2361,83 & 4 \\
\hline 10 & $-8536,55$ & $-2661,72$ & 882,622 & $-3641,11$ & 4 \\
\hline 11 & $-7616,62$ & $-2642,77$ & $-296,88$ & $-1989,9$ & 4 \\
\hline 12 & 2871,13 & $-2708,39$ & $-1427,3$ & $-999,04$ & 5 \\
\hline
\end{tabular}




\begin{tabular}{|c|c|c|c|c|c|}
\hline 13 & 10899,9 & $-5659,91$ & 11283,3 & $-5583,11$ & 5 \\
\hline 14 & 7471,73 & 1367,49 & $-3430,4$ & 8072,98 & 5 \\
\hline 15 & 692,953 & $-5742,52$ & 573,57 & 2388,59 & 6 \\
\hline 16 & 2191,06 & $-553,263$ & $-972,02$ & $-44,2337$ & 6 \\
\hline
\end{tabular}

Pada Tabel I, metode isomap menghasilkan fitur Page|169 yang berdimensi 4 yang dapat dilihat pada kolom 2 sampai dengan kolom 5 (sumbu koordinat 1 sampai dengan sumbu koordinat 4). Pada kolom ke-6 terdapat 6 kategori karena data yang digunakan adalah data dari 6 orang.

TABEL II

FITUR UJI ITERASI KE-1

\begin{tabular}{|c|r|r|r|r|}
\hline & $\begin{array}{c}\text { Sb } \\
\text { Koord 1 }\end{array}$ & $\begin{array}{c}\text { Sb } \\
\text { Koord 2 }\end{array}$ & $\begin{array}{c}\text { Sb } \\
\text { Koord 3 }\end{array}$ & $\begin{array}{c}\text { Sb } \\
\text { Koord 4 }\end{array}$ \\
\hline 1 & 1865,715 & 539,9132 & $-732,798$ & 130,2959 \\
\hline 2 & 2591,17 & $-913,433$ & $-676,285$ & 1808,866 \\
\hline 3 & 258,4072 & 4698,528 & 4139,107 & 3229,985 \\
\hline 4 & $-5018,16$ & 3229,181 & $-3885,48$ & $-3687,17$ \\
\hline 5 & $-8374,26$ & $-2811,57$ & 730,7217 & 1752,626 \\
\hline 6 & $-1417,9$ & $-2787,44$ & $-1472,83$ & $-214,15$ \\
\hline 7 & 2191,061 & $-553,263$ & $-972,016$ & $-44,2337$ \\
\hline 8 & 7471,734 & 1367,492 & $-3430,37$ & 8072,981 \\
\hline
\end{tabular}

Setelah diperoleh fitur-fitur pengenalan citra, tahapan selanjutnya adalah melakukan klasifikasi pada fitur uji (Tabel II) dengan menggunakan algoritma KNN. Hasil klasifikasi pada iterasi ke-1, iterasi ke-2 dan iterasi ke-3 dapat dilihat pada Tabel III, Tabel IV dan Tabel V.

Berdasarkan Tabel III, Tabel IV dan Tabel V, kolom real adalah nilai kategori pada pengamatan sebenarnya, sedangkan pada kolom KNN adalah nilai kategori yang dihasilkan oleh algoritma KNN. Jika nilai kategori real sama dengan kategori dari KNN maka nilai TP adalah sesuai (benar).

TABEL III

PERBANDINGAN HASIL KNN DENGAN PENGAMATAN REAL PADA ITERASI KE-1

\begin{tabular}{|c|c|c|c|}
\hline & \multicolumn{3}{|c|}{ Iterasi ke-1 } \\
\hline & Real & KNN & TP \\
\hline $\mathrm{T} 1$ & 1 & 1 & Sesuai \\
\hline $\mathrm{T} 2$ & 1 & 1 & Sesuai \\
\hline T3 & 2 & 2 & Sesuai \\
\hline $\mathrm{T} 4$ & 3 & 3 & Sesuai \\
\hline $\mathrm{T} 5$ & 4 & 4 & Sesuai \\
\hline T6 & 5 & 5 & Sesuai \\
\hline $\mathrm{T} 7$ & 6 & 1 & Tidak \\
\hline $\mathrm{T} 8$ & 6 & 6 & Sesuai \\
\hline & \multicolumn{2}{|c|}{ Jumlah Sesuai } & 7 \\
\hline & \multicolumn{2}{|c|}{ Akurasi } & $87,5 \%$ \\
\hline
\end{tabular}

TABEL IV

PERBANDINGAN HASIL KNN DENGAN PENGAMATAN REAL PADA ITERASI KE-2

\begin{tabular}{|c|r|r|c|}
\hline & \multicolumn{3}{|c|}{ Iterasi ke-2 } \\
\hline & Real & KNN & TP \\
\hline T1 & 1 & 6 & Tidak \\
\hline T2 & 2 & 2 & Sesuai \\
\hline T3 & 2 & 2 & Sesuai \\
\hline T4 & 3 & 3 & Sesuai \\
\hline
\end{tabular}

\begin{tabular}{|c|c|c|c|}
\hline T5 & 3 & 3 & Sesuai \\
\hline T6 & 4 & 4 & Sesuai \\
\hline T7 & 5 & 5 & Sesuai \\
\hline T8 & 6 & 3 & Tidak \\
\hline & \multicolumn{2}{|c|}{ Jumlah Sesuai } & 6 \\
\hline & \multicolumn{2}{|l|}{ Akurasi } & $75 \%$ \\
\hline
\end{tabular}

TABEL $\mathrm{V}$

PERBANDINGAN HASIL KNN DENGAN PENGAMATAN REAL PADA ITERASI KE-3

\begin{tabular}{|c|c|c|c|}
\hline & \multicolumn{3}{|c|}{ Iterasi ke-3 } \\
\hline & Real & KNN & TP \\
\hline T1 & 1 & 1 & Sesuai \\
\hline $\mathrm{T} 2$ & 2 & 2 & Sesuai \\
\hline T3 & 3 & 3 & Sesuai \\
\hline $\mathrm{T} 4$ & 3 & 3 & Sesuai \\
\hline T5 & 4 & 4 & Sesuai \\
\hline T6 & 4 & 4 & Sesuai \\
\hline T7 & 5 & 5 & Sesuai \\
\hline T8 & 6 & 1 & Tidak \\
\hline & \multicolumn{2}{|c|}{ Jumlah Sesuai } & 7 \\
\hline & \multicolumn{2}{|l|}{ Akurasi } & $87.5 \%$ \\
\hline
\end{tabular}

\section{A. Hasil Evaluasi}

Tahapan selanjutnya adalah menghitung tingkat akurasi dari algoritma KNN dengan menggunakan (5).

$$
\text { Tingkat Akurasi }=\frac{T P}{T P+F P} \times 100 \%
$$

$\mathrm{TP}=$ True Positive (Pengamatan nyata sesuai dengan pengamatan dari komputer)

$\mathrm{FP}=$ False Positive (Pengamatan nyata tidak sesuai dengan pengamatan dari komputer).

Berdasarkan Tabel III dapat dilihat bahwa pada iterasi pertama jumlah sesuai $(\mathrm{TP})=7$ dan tidak sesuai $(\mathrm{FP})=1$, sehingga diperoleh:

$$
\text { tingkat akurasi }=\frac{7}{8} \times 100 \%=87,5 \% \text {. }
$$

Berdasarkan Tabel IV dapat dilihat bahwa pada iterasi kedua jumlah sesuai $(\mathrm{TP})=6$ dan tidak sesuai $(\mathrm{FP})=2$, sehingga diperoleh:

$$
\text { tingkat akurasi }=\frac{6}{8} \times 100 \%=75 \% \text {. }
$$

Berdasarkan Tabel V dapat dilihat bahwa pada iterasi ketiga jumlah sesuai $(\mathrm{TP})=7$ dan tidak sesuai $(\mathrm{FP})=1$, sehingga diperoleh:

$$
\text { tingkat akurasi }=\frac{7}{8} \times 100 \%=87,5 \% \text {. }
$$

Berdasarkan ketiga iterasi tersebut diperoleh

$$
\begin{aligned}
\text { rata }- \text { rata tingkat akurasi } & =\frac{87,5 \%+75 \%+87,5 \%}{3} \\
& =83,33 \%
\end{aligned}
$$




\section{KESIMPULAN}

Pengenalan wajah merupakan salah satu bidang di computer vision yang digunakan untuk mengenali seseorang. Banyak bidang yang memanfaatkan pengenalan wajah ini, salah satunya untuk sistem absensi menggunakan wajah. Wajah seseorang biasanya memiliki ciri khusus (fitur) sehingga mudah dikenali oleh orang-orang. Dalam penelitian ini digunakan metode isomap. Metode isomap merupakan metode reduksi dimensi dari dimensi yang tinggi ke dimensi yang lebih rendah dan digunakan untuk mendapatkan fitur seperti fitur wajah.

Dalam penelitian ini digunakan 24 citra wajah yang terdiri dari 6 orang dengan tiap orang mempunyai 4 citra wajah dengan berbaggai ekspresi. Untuk mendapatkan fitur dari 24 wajah tersebut digunakan metode isomap. Tahapan selanjutnya adalah fitur yang dihasilkan dibagi menjadi dua yaitu 16 fitur latih dan 8 fitur uji. Setelah itu dilakukan pengujian pengenalan wajah dengan menggunakan algoritma KNN. Dari hasil penelitian diperoleh bahwa ratarata tingkat akurasi pengenalan wajah adalah sebesar $83,33 \%$.

Untuk penelitian selanjutnya sampel citra wajah ditambahkan dan sebagai pembanding dilakukan pengujian dengan algoritma lain seperti SVM .

\section{REFERENSI}

[1] R. Kosasih, S. Madenda , C. M. Karyati and Lussiana, "Determination the Optimal Position from $\mathrm{T} 1$ and $\mathrm{T} 2$ Weighted MR Imaging of the Abdominal Aortic Aneurysm," Advance Science, Engineering and Medicine, vol. 7, no. 10, pp. 915-919. 2015.

[2] V. D. Maaten, E. Postma, and V. D. Herik, "Dimensionality reduction a comparative review," L. J. P. Technical Report TiCCTR. pp. 2009-005, 2009.

[3] L. Cayton, "Algorithms for manifold learning," UCSD Technical Report CS. pp. 2008-0923, 2005.

[4] J. B Tenenbaum, V. D Silva and J. Langford, "A global geometric framework for nonlinear dimensionality reduction," Science, vol. 290, pp. 2319-2323, 2002.

[5] R. Kosasih and A. Fahrurozi, "Clustering of Face Images by Using Isomap method," Proceeding on International Workshop on Academic Collaboration, No (ISBN: 978-6029438-86-4), 2017, pp. 52-56.

[6] A. Fahrurozi and R. Kosasih, "Face Recognition Using Local Binary Pattern Combined With PCA For Images Under Various Expression and Illumination," Proceeding on International Workshop on Academic Collaboration, No (ISBN: 978-602-9438-86-4), 2017, pp. 1-7.

[7] D. E. Pratiwi, dan A. Harjoko, "Implementasi Pengenalan Wajah Menggunakan PCA (Principle Component Analysis)," Indonesian Journal of Electronics and Instrumentations Systems, vol. 3, no. 2, pp. 175-184, 2013.

[8] S Warshall. "A Theorem on Boolean Matrices," Journal of the ACM, vol. 9, no. 1, pp. 11-12, 1962.

[9] L. Devroye, L. Gyorfi, A. Krzyzak and G. Lugosi, "On the strong universal consistency of nearest neighbor regression function estimates," Ann. Statist, vol. 22, pp. 1371-1385, 1994.

[10] S. B. Imandoust and M. Bolandraftar, "Application of KNearest Neighbor (KNN) Approach for Predicting Economic Events: Theoretical Background," J. Eng. Res. and App, vol. 3, no. 5, pp. 605-610, 2013.

[11] C. Domeniconi, J. Peng and D. Gunopulos, "Locally adaptive metric nearest-neighbor classification," IEEE Trans. Pattern Anal. Mach. Intell, vol. 24, no.9, pp.1281-1285, 2002.
[12] D. P. Lestari, R. Kosasih, T. Handhika, I. Sari, A. Fahrurozi. "Fire Hotspots Detection System on CCTV Videos Using You Only Look Once (YOLO) Method and Tiny YOLO Model for High Buildings Evacuation," In Proceedings of the 2019 2nd International Conference of Computer and Informatics Engineering (IC2IE), 2019, pp. 87-92. 